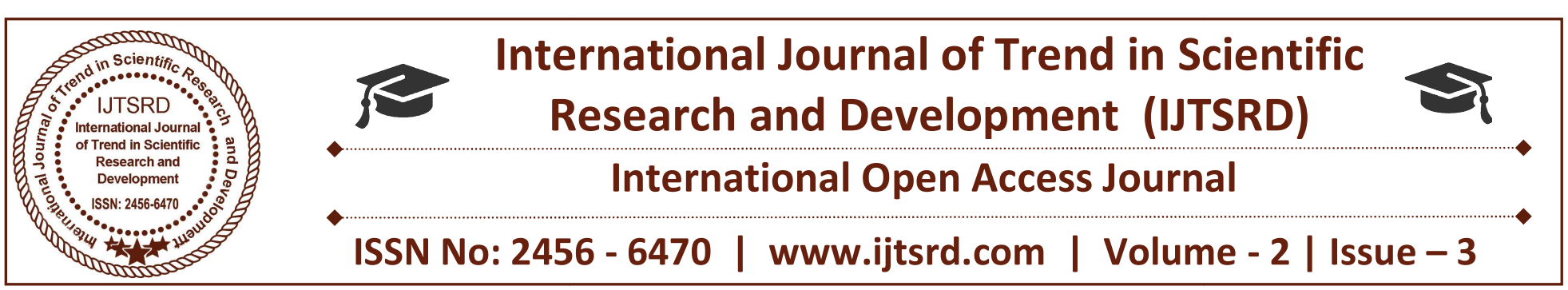

\title{
A Case-Study on Blackout
}

\author{
Abhay Nath Dubey \\ Department of Electrical \\ Engineering, Poornima College of \\ Engineering, Jaipur, Rajasthan
}

\author{
Dr. Deepika Chauhan \\ Associate Professor, Poornima \\ College of Engineering, Jaipur, \\ Rajasthan, India
}

\author{
Md. Asif Iqbal \\ Assistant Professor, Poornima \\ College of Engineering Jaipur, \\ Rajasthan, India
}

\section{ABSTRACT}

Indian grid system is a synchronized system and presently operating as National Grid. India has five provincial grids altogether as per geological region which covers the distinct state's electrical power framework to be specific these are Northern Grid, Eastern Grid, Western Grid, Southern Grid and NorthEastern Grid. Southern Grid isn't synchronized with whatever is left of the areas and consequently keeps running on a marginally different frequency and associated with Western Grid and Eastern Grid through HVDC links.

A power outage is the total or partial loss of energy to a territory and is the most serious type of blackout that can happen. Power outage is a transgression to the interconnected power framework. At the point when interconnected power framework goes out of step, it is basic and essential to distinguish it quickly, and islanding ought to be taken to counteract boundless power outage. Two extreme power outages influenced the greater part of northern and eastern India on $30^{\text {th }}$ and $31^{\text {st }}$ July 2012 . The $30^{\text {th }}$ July 2012 power outage influenced more than 300 million individuals and was the then-biggest power blackout ever, tallying number of individuals influenced, beating the January 2001 India power outage. Within the 24 hours of restoration of this, another blackout strokes the northern part of the country. The outage of $31^{\text {st }}$ July is the biggest power blackout exceeding the previous one.

Keywords: Smart Grid, Overload, Indian Grid, Voltage Collapse, Frequency Stability, Causes and Impact of energy outage, PMU (Phasor measurement unit), RTU (remote terminal unit), TTC (total transfer capability), unscheduled trade

\section{INTRODUCTION}

Power disappointments are especially basic at destinations where the earth and open security are in danger. Organizations, for example, hospitals, sewage treatment plants, mines, and so forth will typically have reinforcement control sources, for example, standby generators, which will naturally start up when electrical power is lost. A power outage is the aggregate loss of energy to a zone and is the most extreme type of energy blackout that can happen. Power outages which result from or result in control stations stumbling are especially hard to recuperate from rapidly. Blackouts may last from a couple of minutes to fourteen days contingent upon the idea of the power outage and the arrangement of the electrical system.[3]

July 2012, is remembered as "Striking End of Summer" by Electrical Engineers. All the regional grid of country are not synchronized and directly connected with each other. "One Nation, One Grid" is still a dream for us. Northern region of the country (Punjab, Haryana, Uttar Pradesh etc.) have larger cultivated land. The demand of power in these states increases tremendously during summer. The imbalance between load and generation causes instability in frequency and leading cascading failure of the line, resulting in Blackout. All major power stations were shut-down in affected states causing total shortage of $32 \mathrm{GW}$. After this incident PGCIL emphasizes the use of Smart Grid appliances and instrument to prevent any such blackout in future. 


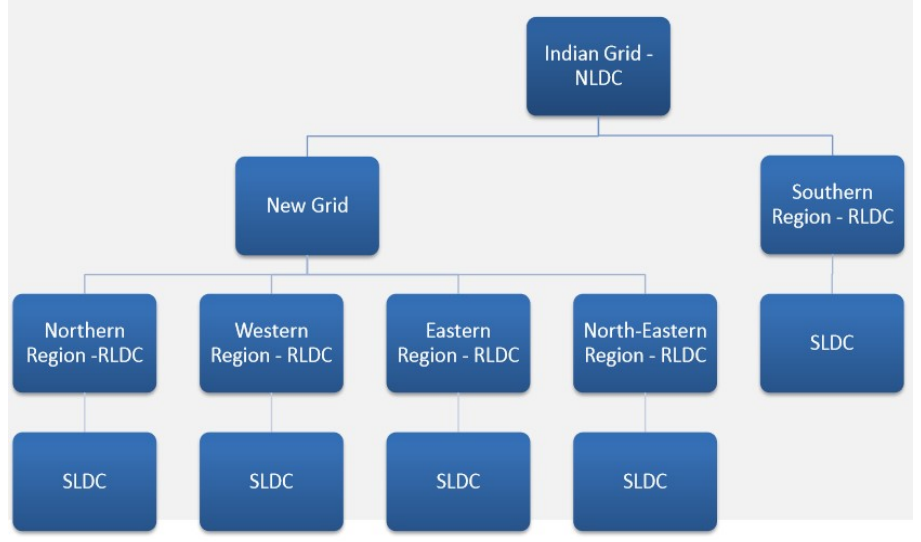

Fig. 1- Grid System in India[16] grids with minor problems, the load is re-balanced by re-routing the power to the lines.

\section{Short circuit}

A short out happens when an electric current goes along a way that is not the same as the expected one out of an electrical circuit. At the point when this happens, there is an unreasonable electric current which can prompt circuit harm, fire, and blast. Truth be told, short-circuits are one of the essential drivers of electrical flames all through the world.[3]

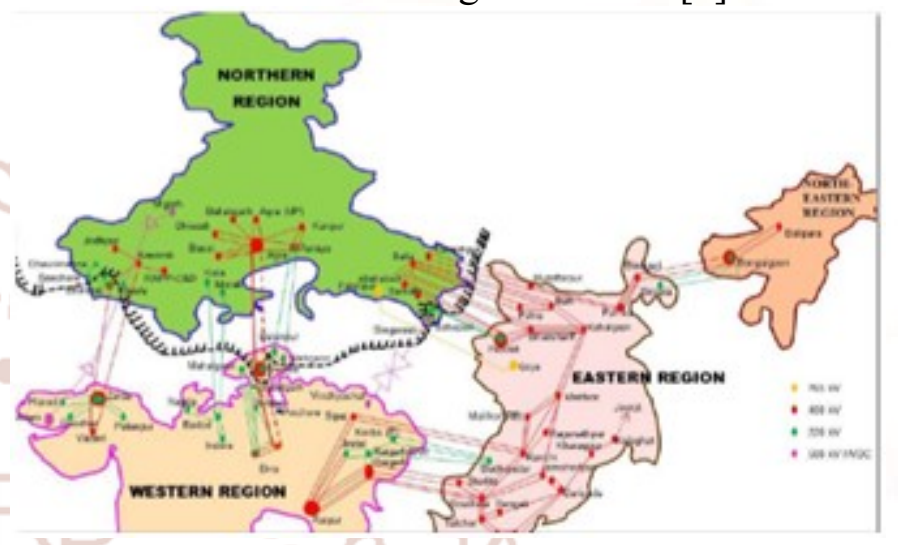

Fig. 2- Layout of New-Grid[16]

\section{Grid Disturbance}

Blackouts result from or result in Grid disturbance and are particularly difficult to recover from quickly. Framework Unsettling influence is stumbling of at least one power framework components of the Lattice bringing about Aggregate Power Disappointment or Supply at a Sub-Station. There have been real network aggravations on the 30 th and the 31 st July 2012 which have influenced expansive parts of the Indian Power Lattices. Because of high load and disappointment of rainstorm, Northern Locale was drawing an extensive quantum of energy from neighboring Western and Eastern Lattices while because of downpours in Western District request was less and it was under illustration. This circumstance prompted a much skewed load age adjust among the districts.

A Grid is said to be disturbed when:

1. There is under-voltage $(\mathrm{U} / \mathrm{V})$

2. There is over-voltage $(\mathrm{O} / \mathrm{V})$

3. There is under-frequency $(\mathrm{U} / \mathrm{F})$

4. There is over-frequency $(\mathrm{O} / \mathrm{F})$

5. There is a rapid fall or rise in electricity $(\mathrm{dF} / \mathrm{dT}$ or $-\mathrm{dF} / \mathrm{dT})$

6. There is a power failure in the grid at generating end (Generation failure)

7. There is a power failure in the grid at transmission part (Loss of transmission) 


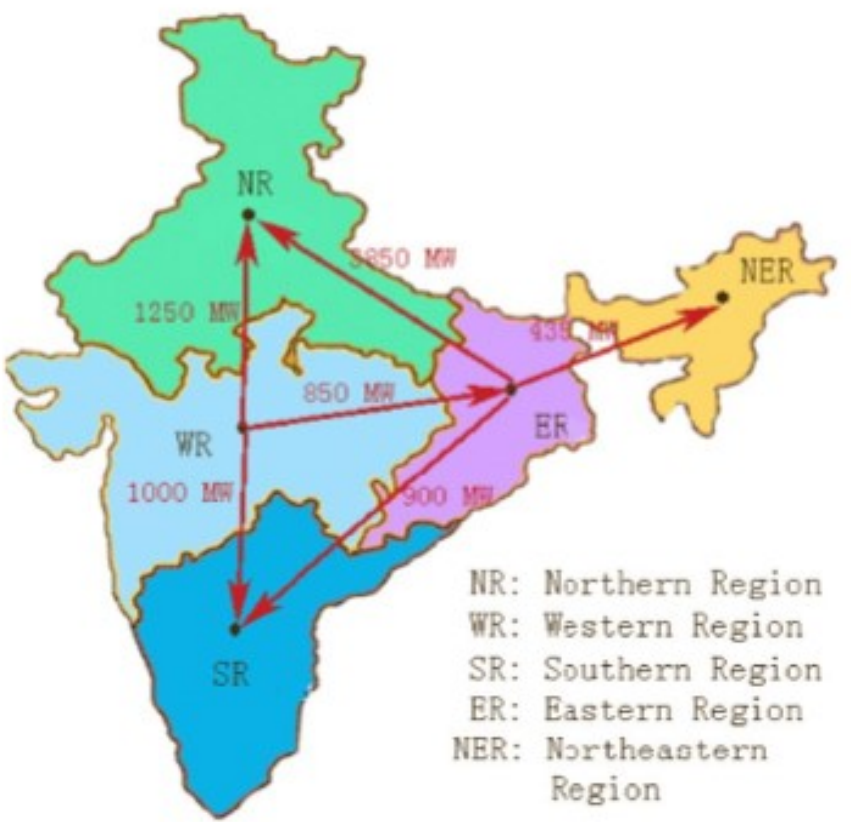

Fig. 3- Transmission capacity graph between the Indian regional grid[15]

\section{POWER BLACKOUT IN INDIA}

India is the world's third biggest power producer and consumer of power after the Unified States and China; be that as it may, the electrical framework is for the most part thought to be questionable. The northern lattice had beforehand crumpled in 2001. An assessed $27 \%$ of vitality produced is lost in transmission or stolen, while top supply misses the mark regarding request by a normal of $9 \%$. The country experiences visit control blackouts that keep going as long as 10 hours. Further, around $25 \%$ of the populace, around 300 million individuals, have no power by any stretch of the imagination due to the 2012 blackout. Endeavors are in progress to decrease transmission and distribution misfortunes and increment creation further. Focuses are on transferring the conventional grid system into a smart grid, where data can be monitored efficiently. Even a small change in system parameter at micro-second level can be tracked and necessary changes can be made to prevent any such system failure. 2012 Blackout was the world's biggest Blackout effecting almost more than 600 million peoples in those two days.

\section{Blackout}

The power disappointment started at 04:30 am (23:00 GMT), after what authorities depicted as a blame in the transmission framework dove quite a bit of north India into obscurity. The Indian power service has declared an enquiry into the crumple of the whole northern power matrix. Power Minister Suresh Prabhu said some portion of the issue was the bungle between constrained supply and expanding request on the framework. "Unless we make coordinate strides... as far as change of framework, making enough speculations into transmission and dissemination... such issues can repeat," he said.

The Confederation of Indian Industry said it was assessed that organizations had lost between 2.5-5 billion rupees $(\$ 107 \mathrm{~m})$ due to the breakdown.

\section{July 2012 Blackout}

July 2012, is recognized as 'Striking End of Summer' by Electrical Engineers. Two enormous and consecutive matrix disappointments happened, coming about the Blackout in North Grid. The Indian power framework experienced two separate gigantic power outages on 30th and 31st of July 2012. These power outages uncovered a progression of characteristic issues basic the power arrangement of India, for example, its age arranging, transmission arranging, lattice foundation, administration frameworks, essential vitality assets, natural limitations, power market, and data innovation, which together exasperate the enormous power outages. These components which influence the sufficiency and security of the power supply in a comparative way as the transmission clog of physical matrices does, can be called by a bland term as summed up blockage.

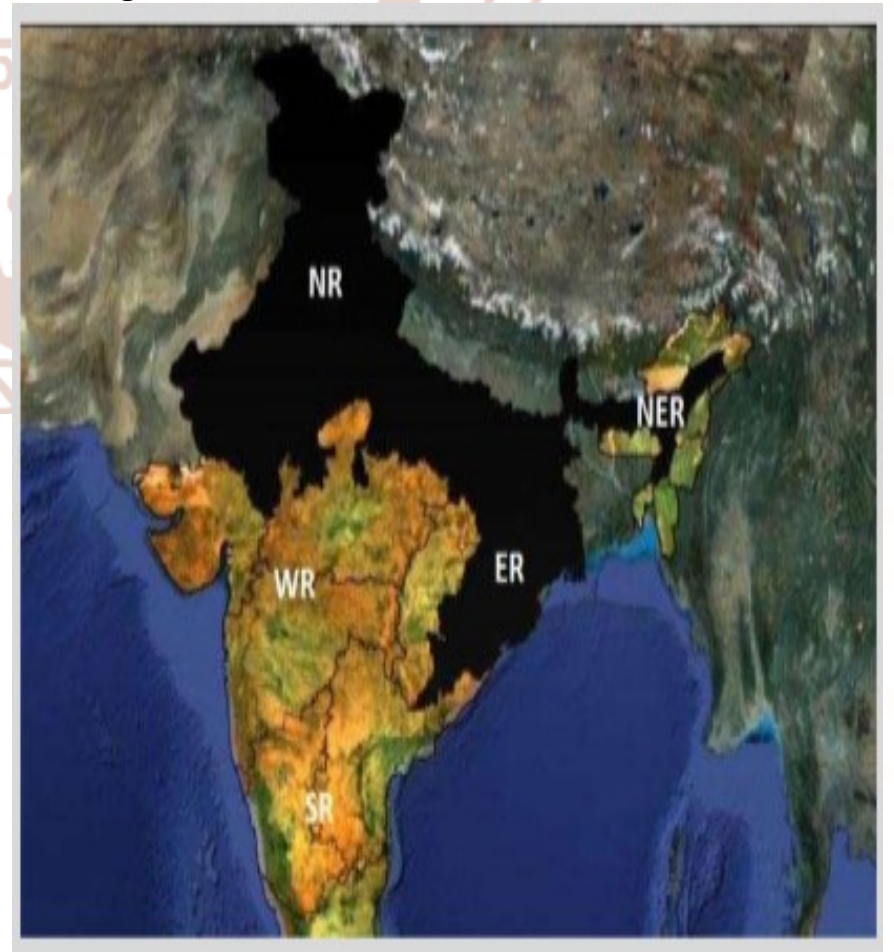

Fig. 4- Effected States and regions[1] $30^{\text {th }}$ July $1^{\text {st }}$ Blackout 
An unsettling influence happened in the Northern India power network at 02:33 hours of 30th July 2012 prompting a power outage in almost the whole Northern district covering all the 8 States i.e., the States of Delhi, Uttar Pradesh, Uttarakhand, Rajasthan, Punjab, Haryana, Himachal Pradesh and Jammu and Kashmir and also the Union Territory of Chandigarh. The recurrence just before the episode was $49.68 \mathrm{~Hz}$. The All India Demand met before the occurrence was around $99700 \mathrm{MW}$ and the request being met in the Northern Region was around 38000 MW.

An electrical switch at $400 \mathrm{kV}$ Bina-Gwalior line get stumbled which encouraged the Agra-Bareilly transmission line, breakers at the station likewise stumbled, and control disappointments fell through the lattice. All real power stations were closed down at influenced states. The Northern Region Grid crumbled because of expanded load and brace aggravation leaving nine conditions of Northern India frail including Delhi, the capital of India. It was India's biggest power outage till 30th July 2012 and Nearly 350 million endured because of this power blackout which came about for about a day.

Coordinate reason for power outage incorporates power supply limit neglecting to take care of developing demand. Especially, hydroelectric power yield, which represents right around $15 \%$ of nation's aggregate power age, was somewhere in the range of $20 \%$ not exactly the standard because of drafts. Besides, draft builds the interest for power to pump up groundwater for farming water system.

India needs to take assistance from minor Bhutan to reestablish its supply. Administration of India has consented to help Bhutan to create hydro control and will buy no under $10000 \mathrm{MW}$ of the power from Bhutan by 2020. India will import power from Tala, Bhutan to calm the weight from substantial stacking amid summer.[2]

\section{$31^{\text {st }}$ July $2^{\text {nd }}$ Blackout}

Within 24 hours of rebuilding work, again the Northern area lattice crumbled for the second time on 31 , July 2012 at around 1pm nearby time on Tuesday. The power outage on 31 July is the biggest power blackout ever. The blackout influenced more than 620 million individuals, around $9 \%$ of the total populace or half of India's populace. This time the sudden power blackout brought about fall of two more territorial braces to be specific, the Eastern and the North-Eastern local Grids which spread crosswise over 20 of India's 28 states leaving around 620 million individuals influenced. Half of India's states like Delhi, Bihar, Orissa, Punjab, Haryana, Rajasthan, Uttar Pradesh and so on were confronting power outage Tuesday with more issues like gigantic roads turned parking lots due to fizzled movement lights, mineworkers being caught underground as lifts fizzled, metro administrations going to a stop and individuals were left searing in the late spring heat.

This time the sudden power blackout brought about crumple of two more local braces to be specific, the Eastern and the North-Eastern local Grids which spread crosswise over 20 of India's 28 states leaving around 620 million individuals influenced.

The unsettling influence happened at 13:00 hours of 31 st July 2012 influenced the Northern, Eastern and North-Eastern power networks. The recurrence before the episode was $49.84 \mathrm{~Hz}$. The All India Demand Met only preceding the episode was around 100,500 MW and the request being met in the NEW Grid was $73000 \mathrm{MW}$ roughly. Roughly 48000MW of customer stack crosswise over 21 States and 1 Union Territory was influenced by the framework unsettling influence. The regions which survived included Western Region, creating units at Narora Atomic Power Station, Anta GPS, Dadri GPS and Faridabad GPS and also part of Delhi framework in NR and framework involving Sterlite/IB TPS, Bokaro Steel and CESC Kolkata frameworks in ER.[16]

\section{Investigation}

Upon the arrival of the fall, Power Minister 'Shushil Kumar Shinde' expressed that the correct reason for the disappointment was obscure, yet that at the season of the disappointment, power utilize was "above ordinary". The priest stated, in the late spring, "states attempt to take more power from the network" and at the season of the crumple, the matrix recurrence was "above typical".

Central Electricity Regulatory Commission (CERC) has given a bearing to examine into the rates of framework disappointment on 30th July 2012 and 31st July 2012. The three-part examination board of trustees comprised of S. C. Srivastava, A. Velayutham and A. S. Bakshi, and issued its provide details regarding 16 August 2012. 
It is presumed that central point in charge of the two days of power outages were:

- Weak between local power transmission hallways because of various existing blackouts (both booked and constrained)

- High stacking on $400 \mathrm{kV}$ Bina- Gwalior- Agra connect

- Improper Communication in-between State Load dispatch Centre and National load dispatch Centre and lack of coordination between them

- Loss of $400 \mathrm{kV}$ Bina- Gwalior connect because of disoperation of its assurance framework.

Recommendations of the Committee

The panel likewise offered various suggestions to forestall promote disappointments, including a review of the assurance frameworks.

\section{Technical Recommendations}

- Review security plots alongside Immediate audit of zone-3 logic

- Synchro-phasor estimations from PMUs ought to be investigated for assurance frameworks

- A finish autonomous review of time synchronization of DRs, ELs and PMUs

- Frequency band taking care of near $50 \mathrm{~Hz}$

- Review of UI instrument

- STUs ought to promptly empower eunder recurrence and $\mathrm{df} / \mathrm{dt}$ based load shedding plans

- Faster calculation for count of TTC

- The administrative arrangements in regards to ingestion of responsive power by producing units should be actualized

- The Communication system ought to be reinforced

- Focus ought to be given to expand the Distributed Generation of EnergyEnergy

\section{Policy Recommendations}

- Implementation of different controls issued under the Electricity Act, 2003 and investigate infringement SERIOUSLY

- Real-time security work area in every one of the movements to be kept an eye on by design fit for completing TTC figuring (in NLDC and RLDC)

- LDC and Regulatory Commissions identified with rebelliousness of administrative arrangements including that for resistance of headings and noninstallment of UI charges, require survey[16]

- Training and confirmation of framework administrators should be given centered consideration
- There is have to strengthen framework think about gatherings in control area associations to examine the framework conduct

- A Special Task compel is should be framed for continuous checking and investigation of line information and to speak with rest of the network part

\section{Future and Conclusion}

Power transfer constrain in the system should be expanded to enhance the effectiveness of existing force plants. This would require a lot of cash. Henceforth, gigantic venture are to be made in this area. Our matrix frameworks need to change from the traditional one into a Smart Grid bit by bit. Constant observing and correspondence however the framework is the basic part in making the matrix more intelligent. Monitoring of system parameter is a crucial part of smart grid. Smart Meter, Phasor Measurement Unit, Synchro- Phasor and automated scada systems are need to make our grid system smart. By using these technologies we can monitor even a small disturbance in grid parameter and recover from any damage.

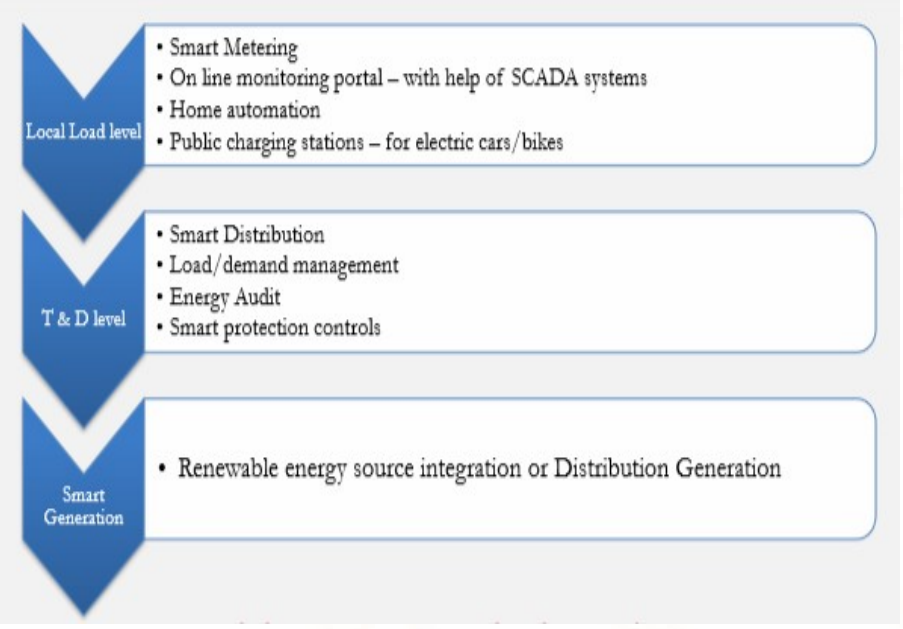

Fig. 5- Features of Smart Grid[16]

\section{REFERENCES}

1. "A Qualitative analysis of Power System Blackouts- Northern Grid Case Study" By Sujata Shiv Ashimpiger, Siridevi.N.C., Parthasarathy.V, Dr. H.M.Ravikumar, International Journal of Emerging Trends in Engineering Research (IJETER), Vol. 3 No.6, Pages : 373 - 379 (2015)

2. "Lesson Learned from July 2012 Indian Blackout" By Loi Lei Lai, FIEEE, Hao Tian Zhang MIEEE, S.Mishra, Deepak 
International Journal of Trend in Scientific Research and Development (IJTSRD) ISSN: 2456-6470

Ramasybramanian, Chung Sing Lai, Fang Yuan Xu, MIEEE(2012)

3. "Blackouts in the Power System" By Sudeep Dattatraya Kulkarniirlekar, International Journal of Electrical and Electronics Research ISSN 2348-6988 (online)(2015)

4. "Power cut off and Power Blackout in India a Major threat- An Overview" By Md. Moyeed Abrar, International Journal of Advancements in Research \& Technology, Volume 5, Issue 7, July-2016 8 ISSN 2278-7763

5. "Statistical Analysis of Cost of Energy Due to Electrical Outages in Developing Countries" By Venkat Natarajan and Amit S. Closepet, FUTURE COMPUTING 2012 : The Fourth International Conference on Future Computational Technologies and Applications

6. "Survey of Indian Power Grid: Overview and Challenges" By Gresha S Bhatia and J.W. Bakal, International Journal of Computer Applications ${ }^{\circledR}$ (IJCA) $(0975$ - 8887)

7. "A worrisome Blackout in India" By S Narayana, ISAS Insights No. 177 - 7 August 2012

8. "Aspect of Power System Islanding for preventing widespread Blackout" By Yuanqi Liu and Yitian Liu, DOI: 10.1109/ICNSC.2006.1673304 Source: IEEE Xplore (2006)

9. "Investigation on July 2012 Indian Blackout" By Loi Lei Lai, Hao Tian Zhang, Chun Sing Lai, Fang YuanXu, Sukumar Mishra, International Conference on Machine Learning and Cybernetics, Tianjin, 14-17 July, 2013
10. "New Technique for the Prevention of Power System Collapse" By F.A. Shaikh, Ramanshu Jain, Mukesh Kotnala, Nickey Agarwal, IEEE (2013)

11. "Indian Experience on Smart Grid Application in Blackout Control" By Sayan Sarkar, Gairik Saha, Gaurav Pal, Taniya Karmakar

12. "Generalized Congestion of Power System: insights from the massive blackouts in India" By Yusheng Xue, , J. Mod. Power Syst. Clean Energy (2013) 1(2):91-100

13. "Background and impact of World"s Largest Blackout in India" By Ken Koyama, IEEJ(2012)

14. "Power System Frequency Stability and Control: Survey" By Bashar Sabeeh Abdulraheem and Chin Kim Gan, International Journal of Applied Engineering Research ISSN 09734562 Volume 11, Number 8 (2016) pp 5688-5695

15. "Understanding the Cascading Failure of Indian Power Grids with complex Networks Theory" By Guidong Zhang, Zong Li, Bo Zhang, Wolfgang A. Halang, ELSEVIER(2013)

16. "Report on Grid Disturbance" By CERC Order in Petition No. 167/Suo-Motu/2012 dated 1st Aug2012 